\title{
A systematic review of perceived risks, psychological and behavioral impacts of genetic testing
}

Jodi T. Heshka, MD, MSc ${ }^{1}$, Crystal Palleschi, MSc ${ }^{1}$, Heather Howley, MSc ${ }^{1}$, Brenda Wilson, MRCP (UK), MFPHM (UK) ${ }^{1}$, and Philip S. Wells, MD, FRCPC ${ }^{1,2}$

\begin{abstract}
Genetic testing may enable early disease detection, targeted surveillance, and result in effective prevention strategies. Knowledge of genetic risk may also enable behavioral change. However, the impact of carrier status from the psychological, behavior, and perceived risk perspectives is not well understood. We conducted a systematic review to summarize the available literature on these elements. An extensive literature review was performed to identify studies that measured the perceived risk, psychological, and/or behavioral impacts of genetic testing on individuals. The search was not limited to specific diseases but excluded the impacts of testing for single gene disorders. A total of 35 articles and 30 studies were included. The studies evaluated hereditary nonpolyposis colorectal carcinoma, hereditary breast and ovarian cancer, and Alzheimer disease. For affective outcomes, the majority of the studies reported negative effects on carriers but these were short-lived. For behavioral outcomes, an increase in screening behavior of varying rates was demonstrated in carriers but the change in behaviors was less than expected. With respect to perceived risk, there were generally no differences between carriers and noncarriers by 12 months after genetic testing and over time risk perception decreased. Overall, predispositional genetic testing has no significant impact on psychological outcomes, little effect on behavior, and did not change perceived risk. It seems as though better patient education strategies are required. Our data would suggest better knowledge among carriers would not have significant psychological impacts and therefore, it is worth pursuing improved educational strategies. Genet Med 2008:10(1):19-32.
\end{abstract}

Key Words: systematic review, genetic testing, perceived risk, behavioral outcomes, psychological outcomes

The recent identification of various gene mutations associated with disease has made possible the use of mutation analysis to identify unaffected individuals at increased risk of specific conditions. Genetic testing thus has the potential to lower morbidity and mortality through early disease detection and targeted surveillance and prevention strategies. For some conditions, such as multiple endocrine neoplasia type 2 and Huntington disease, genetic testing is highly predictive. However, for multifactorial diseases such as colorectal cancer, breast and ovarian cancer, and Alzheimer disease (AD), genetic testing is less determinative and more "predispositional" in nature. In these cases, genetic risk prediction can help identify individuals at increased risk but, doing so may result in increased distress, anxiety, and stigmatization.

\footnotetext{
From the ${ }^{1}$ Department of Epidemiology and Community Medicine, University of Ottawa, Ottawa, Ontario, Canada; and ${ }^{2}$ Ottawa Health Research Institute, The Ottawa Hospital, Ottawa, Ontario, Canada.

Dr. Philip S. Wells, MD, The Ottawa Hospital, Suite F 649-1053 Carling Avenue, Ottawa, ON, Canada K1Y4E9.E-mail: pwells@ohri.ca.

Disclosure: The authors declare no conflict of interest.

Submitted for publication August 7, 2007.

Accepted for publication September 24, 2007.

DOI: $10.1097 /$ GIM.0b013e31815f524f
}

The focus in genetics research has recently been the impact of testing on individuals and their families. To date, the majority of published research on complex disorders has focused on hereditary forms of colorectal, breast, and ovarian cancers, and Alzheimer disease although the latter is not currently used for clinical purposes. Colorectal cancer is one of the most common cancers in North America. The cumulative lifetime risk of colorectal cancer for the average individual is estimated to be around $5-6 \% .{ }^{1} \mathrm{He}-$ reditary nonpolyposis colorectal carcinoma (HNPCC) is the most common hereditary colon cancer syndrome and is associated with one of five germline mutations ( $h M S H 2, h M L H 1, P M S 1$, PMS2, and hMSH6)..$^{2-5}$ Mutations in these genes result in a lifetime colorectal cancer risk of approximately $80-85 \% .6,7$ Women with either a $B R C A 1$ or $B R C A 2$ gene mutation have a $56-87 \%$ and $10-60 \%$ lifetime risk of breast and ovarian cancer, respectively, compared with the general white population risks of 12.67 and $1.44 \% .{ }^{8}$ Increased risk of $\mathrm{AD}$ is associated with the apolipoprotein $\mathrm{E} 4$ allele. In comparison with other apolipoprotein $\mathrm{E}$ genotypes, the presence of this allele is associated with approximately a 3-fold increase in risk of $\mathrm{AD}$; two copies of the allele increases risk 15 - to 30 -fold. ${ }^{9}$

As the genetic basis for complex multifactorial illnesses continues to be established, testing for relevant predispositional genes may become a legitimate element of clinical diagnosis and management of these illnesses. As this situation evolves, it 
is important to examine the implications of genetic testing from the perspectives of patients and their families. A number of reviews investigating the impact of genetic counseling and testing have been published. For the most part, these reviews have focused on predictive testing, single mutations (e.g., $B R C A 1 / 2$ ), genetic counseling alone, perceived risk, psychological impacts alone, or behavioral impacts alone. Few reviews have focused on predispositional testing or have examined the collective psychological and behavioral impacts of testing. The aim of this review is therefore to summarize recently published data describing the perceived risk, affective and behavioral impacts of undergoing predispositional genetic testing.

\section{METHODS}

\section{Search strategy}

Five electronic databases were searched using the OVID search interface: MEDLINE, EMBASE, Cochrane Central Register of Controlled Trials, CINAHL, and PsycINFO. Each database search was conducted during the week of November 27, 2006, and all search results were limited to the years $2000-$ 2006. A detailed search strategy was developed for use in MEDLINE and then adapted for each database. Search terms were based on the general categories of genetics and genetic testing, psychological factors and behavioral factors (Table 1). The reference lists of all relevant articles (including reviews) were examined for reports of additional studies, and retrieved by searching bibliographic databases and electronic journals. Also, the Science Citation Index (via Web of Science) was searched to find reports that had cited relevant studies. Key authors in this subject area were identified from these studies and used as additional search terms in the five electronic databases listed earlier.

\section{Selection of eligible articles}

Studies were included in this review if they (1) were published in a peer-reviewed journal in English; (2) included adult, human subjects; (3) evaluated the perceived risk, psychological, and/or behavioral impacts of genetic testing on individuals with a family history of any multifactorial adult onset genetic disorder; and (4) reported separate results for carriers and/or noncarriers. Studies were excluded if they (1) assessed only the intention to undergo genetic testing; (2) assessed the impacts of genetic counseling where subjects did not receive genetic test results; (3) assessed the impacts of genetic testing where subjects were already affected with the disorder in question (or where results were combined for affected and unaffected subjects); (4) assessed the impacts of testing for single gene disorders (e.g., Huntington disease); and (5) were studies of prenatal or childhood genetic testing.

Both randomized controlled trials and prospective studies were considered for this review, whereas qualitative studies and case reports were excluded. Outcomes of interest were perceived risk, affective (e.g., general distress, anxiety, depression, and disorder-specific worry), and behavioral (e.g., surveillance, screening uptake, lifestyle changes). With respect to perceived risk and affective outcomes, pre- and posttest data were required for inclusion. Posttest data alone for behavioral outcomes were sufficient for inclusion.

Reviews, editorials, letters to the editor, book reviews, and commentaries were excluded. A single reviewer independently screened the titles and abstracts of each remaining citation, and excluded studies based on the inclusion/exclusion criteria. If it was unclear whether the study met these criteria, the reviewer obtained the full text of the report for independent assessment. Two reviewers independently assessed the eligibility of all potentially eligible full-text studies, and any discrepancies were resolved through discussion and/or a third reviewer. All excluded studies and reasons for exclusion were documented.

\section{Information extraction}

Two reviewers independently abstracted data from all studies meeting the inclusion criteria using a piloted information extraction sheet. Discrepancies were resolved through discussion. Information was collected regarding study characteristics, study design, population, and outcomes (perceived risk, affective, behavioral). The reviewers were not blinded to the names of authors, journal, or institutions.

\section{Quality assessment}

A formal quality assessment was not performed, as the vast majority of studies were prospective, nonrandomized studies, and all well-validated quality assessment tools are intended for use with randomized controlled trials.

\section{RESULTS}

\section{Study characteristics}

A flow diagram of the search results is illustrated in Figure 1. The electronic database searches generated 1289 citations; from these abstracts, 139 reports were fully reviewed for eligibility. From these reports, a total of 35 articles and 30 studies met the inclusion criteria for the review (Table 2). In three instances, two separate studies were published using data collected from one large population..$^{11,12}$ However, because each study seemed to use different subsamples from the one larger population, or reported different outcome measures in each article, they were considered as separate studies.

In total, 16 studies assessed the impacts of genetic testing for hereditary breast and ovarian cancer (HBOC), ,1-30 11 for HNPCC, ${ }^{31-41}$ one for both HBOC and HNPCC, ${ }^{42}$ and two for AD. ${ }^{43,44}$ In the studies on HBOC, the vast majority of participants were female. One study included both men and women ${ }^{13}$ whereas another was specifically designed to assess the impact of genetic testing on behavior in men. ${ }^{14}$ Studies on HNPCC and $\mathrm{AD}$ included both male and female participants. Affective outcomes measured in the studies included disorder-specific distress, general and state anxiety, depression, mood state, cancer worry, general distress, and psychiatric diagnosis. Table 3 summarizes the general and specific outcome measures of the studies included in this review. Behavioral outcomes included surveillance behaviors (e.g., mammography, breast exams, 
Table 1

Review search strategy

\begin{tabular}{|c|c|c|c|}
\hline MEDLINE/CENTRAL & EMBASE & CINAHL & PSYCINFO \\
\hline 1. genetic diseases, inborn/ & 1. exp human genetics/ & 1. genetics, medical/ & 1. genetic counseling/ \\
\hline 2. genetics, medical/ & 2. genetic disorder/ & 2. Hereditary Diseases/ & 2. genetic disorders/ \\
\hline 3. genetic screening/ & 3. exp genetic service/ & 3. genetic screening/ & 3. genetic testing/ \\
\hline 4. exp genetic services/ & 4. genetic analysis/ & 4. genetic counseling/ & 4. genetic disorder\$. tw. \\
\hline 5. genetic disorder\$. tw. & 5. genetic disorder\$. tw. & 5. genetic disorder\$. tw. & 5. genetic test\$. tw. \\
\hline 6. genetic test\$. tw. & 6. genetic test\$. tw. & 6. genetic test\$. tw. & 6. genetic screen\$. tw. \\
\hline 7. genetic screen\$. tw. & 7. genetic screen\$. tw. & 7. genetic screen\$. tw. & 7. genetic risk\$. tw. \\
\hline 8. genetic risk\$. tw. & 8. genetic risk\$. tw. & 8. genetic risk\$. tw. & 8. genetic counsel\$. tw. \\
\hline 9. genetic counsel\$. tw. & 9. genetic counsel\$. tw. & 9. genetic counsel\$. tw. & 9. PSYCHOLOGY/ \\
\hline 10. psychology/ & 10. psychology/ & 10. PSYCHOLOGY/ & 10. DISTRESS/ \\
\hline 11. adaptation, psychological/ & 11. mental stress/ & 11. ANXIETY/ & 11. ANXIETY/ \\
\hline 12. stress, psychological/ & 12. anxiety/ & 12. DEPRESSION/ & $\begin{array}{l}\text { 12. "DEPRESSION (EMOTION)"/or MAJOR } \\
\text { DEPRESSION/ }\end{array}$ \\
\hline 13. anxiety/ & 13. depression/ & 13. somatoform disorders/ & 13. SOMATIZATION \\
\hline 14. depression/ & 14. somatization/ & 14. "psychosocial aspects of illness"/ & 14. anxiety. tw. \\
\hline 15. somatization/ & 15. anxiety. tw. & 15. anxiety. tw. & 15. depression. tw. \\
\hline 16. anxiety. tw. & 16. depression. tw. & 16. depression. tw. & 16. psychologic $\$$ distress. tw. \\
\hline 17. depression. tw. & 17. psychologic $\$$ distress. tw. & 17. psychologic $\$$ distress. tw. & 17. somatiz\$. tw. \\
\hline 18. psychologic\$ distress. tw. & 18. risk management/ & 18. somatiz\$. tw. & 18. risk management/ \\
\hline 19. somatiz\$. tw. & 19. risk reduction/ & 19. risk management/ & 19. health Behavior/ \\
\hline 20. risk management/ & 20. health behavior/ & 20. health behavior/ & 20. coping behavior/ \\
\hline 21. risk reduction behavior/ & 21. coping behavior/ & 21. behavioral changes/ & 21. risk perception/ \\
\hline 22. health behavior/ & 22. health behavior\$. tw. & 22. adaptation, psychological/ & 22. health behavior\$. tw. \\
\hline 23. health behavior\$. tw. & 23. perceived risk\$. tw. & 23. health behavior\$. tw. & 23. perceived risk\$. tw. \\
\hline 24. perceived rsik\$. tw. & 24. perceived control\$. tw. & 24. perceived risk\$. tw. & 24. perceived control\$. tw. \\
\hline 25. perceived control\$. tw. & 25. fatalis $\$$. tw. & 25. perceived control\$. tw. & 25. fatalis $\$$. tw. \\
\hline 26. fatalis\$. tw. & 26. adult/ & 26. fatalis\$. tw. & 26. or/1-8 \\
\hline 27. adult/ & 27. or/1-9 & 27. ADULT/ & 27. or/9-17 \\
\hline 28. or/1-9 & 28. or/10-17 & 28. or/1-9 & 28. or/18-25 \\
\hline 29. or/10-19 & 29. or/18-25 & 29. or/10-18 & 29.26 and 27 \\
\hline 30. or/20-26 & 30.27 and 28 & 30. or/19-26 & 30. limit 29 to $y r=" 1999-2006 "$ \\
\hline 31.28 and 29 & 31. limit 30 to $\mathrm{yr}=" 1999-2006 "$ & 31.28 and 29 & 31. limit 30 to human \\
\hline 32. limit 31 to $\mathrm{yr}=" 1999-2006 "$ & 32. limit 31 to human & 32. limit 31 to $\mathrm{yr}=$ "1999-2006" & 32.26 and 28 \\
\hline 33. limit 32 to humans & 33.32 and 26 & 33.32 and 27 & 33. limit 32 to $y r=" 1999-2006 "$ \\
\hline 34.33 and 27 & 34.27 and 29 & 34. 28 and 30 & 34. limit 33 to human \\
\hline 35.28 and 30 & 35. limit 34 to $\mathrm{yr}=" 1999-2006 "$ & 35. limit 34 to $y r=" 1999-2006 "$ & 35.31 or 34 \\
\hline 36. limit 35 to $y r=" 1999-2006 "$ & 36. limit 35 to human & 36.35 and 27 & 36. prenatal diagnosis/ \\
\hline 37. limit 36 to humans & 37.36 and 26 & 37.33 or 36 & 37.35 not 36 \\
\hline 38.37 and 27 & 38.33 or 37 & & \\
\hline 39.34 or 38 & 39. prenatal diagnosis/ & & \\
\hline 40. prenatal diagnosis/ & 40.38 not 39 & & \\
\hline 41.39 not 40 & & & \\
\hline
\end{tabular}




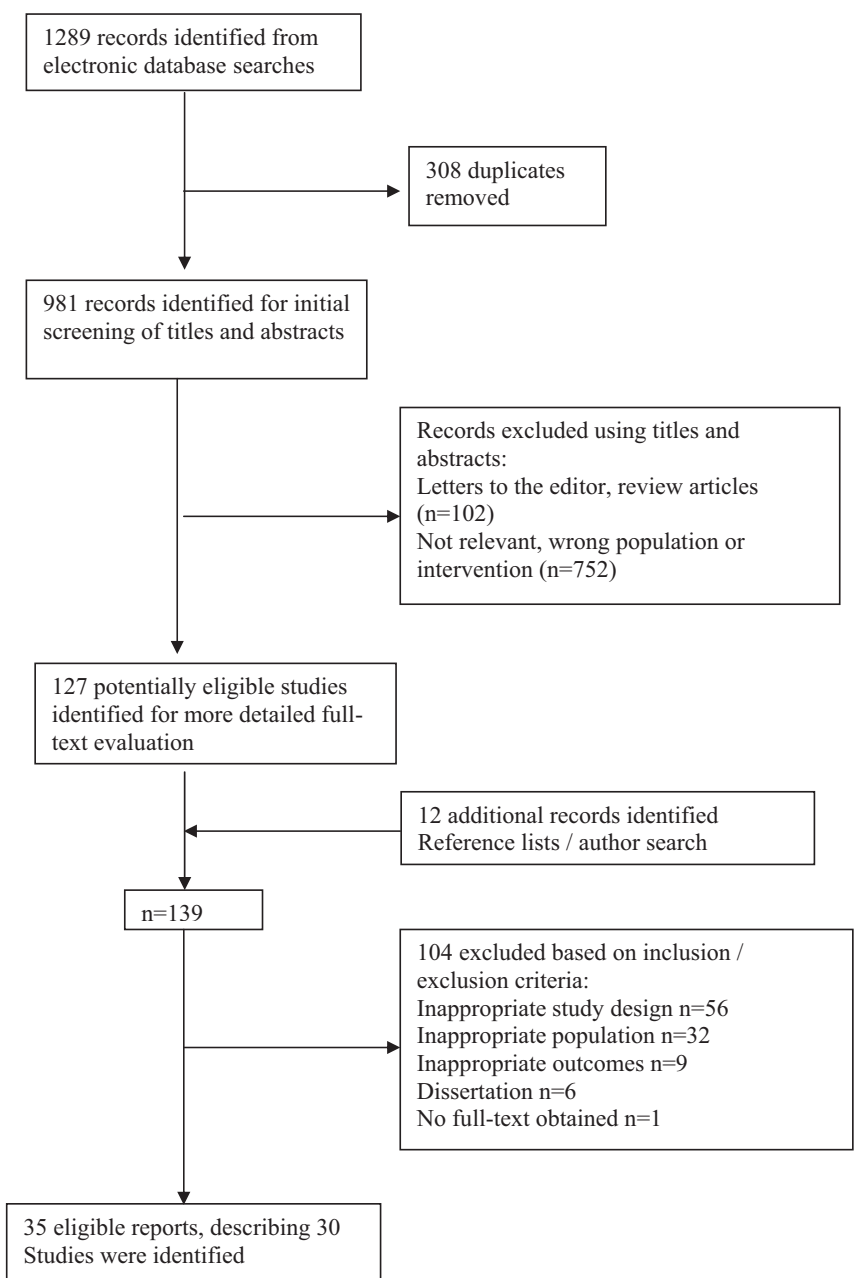

Fig. 1. QUOROM ${ }^{10}$ flow diagram outlining the results of the literature search and the selection of studies for inclusion in the review.

transvaginal ultrasound, colonoscopy), prophylactic surgery (e.g., bilateral mastectomy or oophorectomy), and other preventive behaviors (e.g., chemotherapeutics, diet, exercise).

\section{Affective outcomes}

The studies assessing the impact of genetic testing for HBOC, HNPCC, and AD on affective outcomes pre- and posttesting in mutation carriers and noncarriers, and between carriers and noncarriers, are summarized in Table 4. General and specific distress, anxiety, depression, and worry were the outcome measures studies most frequently measured and will therefore be the focus of review.

\section{General distress}

Seven studies assessed general distress after genetic testing. The instruments used to assess general distress included the hospital anxiety and depression scale (HADS), the general health questionnaire-28, the Hopkins symptom checklist- 25 or the symptom checklist- 90 . The majority of studies, irrespective of disease, found no effect of genetic testing for either carriers or noncarriers. Similarly, most studies found no difference between carriers and noncarriers after disclosure of test results. Two studies on $\mathrm{HBOC}^{13,19}$ found that general distress was higher in carriers compared with noncarriers in the short term (i.e., 1 week to 4 months), whereas one study on HNPCC found that, while there was no change in distress for carriers in the long term (i.e., 12 months), noncarriers had lower general distress than carriers at 12 months follow-up. ${ }^{33}$ An additional study found that not only did noncarriers have lower distress at 12 months, but so did carriers opting for surveillance strategies when compared with carriers opting for prophylactic mastectomy. ${ }^{22}$ Neither of the studies on AD assessed the impact of genetic testing on general distress.

\section{Specific distress}

Sixteen studies examined the impact of genetic testing on cancer-specific distress, all using the impact of events scale. Eleven of these studies were on HBOC, four were on HNPCC, and one was on $\mathrm{AD}$.

For HBOC, the majority of studies reported decreases in specific distress in the short term (i.e., 1 month) and the long term (i.e., 12 months) irrespective of carrier status. Two studies found no effect of genetic testing on specific distress in either carriers or noncarriers, or between groups. ${ }^{21,28} \mathrm{~A}$ single study found that cancer-specific distress increased in carriers in the very short term (i.e., 2 weeks). ${ }^{30}$ An equal number of studies $(n=2)$ found a decrease in specific distress in noncarriers compared with carriers or no difference between the two groups. A single study found specific distress increased in carriers compared with noncarriers at 1, 4, and 12 months. ${ }^{13}$

For HNPCC mutation carriers, studies found that genetic testing either had no effect on cancer-specific distress, or noted that distress increased in the short term (i.e., 2 weeks) and then returned to baseline levels. For noncarriers, specific distress either decreased after test result disclosure or did not change. In comparing carriers and noncarriers, noncarriers generally had lower cancer-specific distress than carriers. One study reported no difference between groups, but specific distress in this study was only assessed at 1 month after disclosure of genetic test results. ${ }^{33}$

Similarly, the single study assessing specific distress after genetic testing for $\mathrm{AD}$ reported no effect in carriers over time, but lower specific distress in noncarriers than carriers at all time points ( 6 weeks, 6 months, and 12 months).

\section{Anxiety}

Fifteen studies measured anxiety after genetic testing, most using the State-Trait Anxiety Inventory, two studies the HADS; one used the Beck Anxiety Inventory. ${ }^{43}$

For HBOC, 13 studies reported no difference between pretest and posttest anxiety levels among carriers at 12 months. One study found that anxiety had decreased 1 month posttest, ${ }^{11}$ a second larger study found it had increased at 2 weeks, ${ }^{30}$ and a third found increased levels of anxiety at 5 years when compared with 1 year. ${ }^{21}$ Results were similar for noncarriers, with the majority of studies reporting no effect 
Table 2

Summary of included studies $(n=35)$

\begin{tabular}{|c|c|c|c|c|}
\hline Authors & Condition & Country & Assessment timepoints & Outcomes \\
\hline Aktan-Collan et al. ${ }^{31}$ & HNPCC & Finland & Base, DS, $1 \mathrm{mo}, 12 \mathrm{mo}$ & Perceived risk; Affective State Anx, Worry \\
\hline Andrews et al. ${ }^{15}$ & HBOC & Australia & Base, 7-10 days, $1 \mathrm{mo}, 12 \mathrm{mo}$ & Affective: Spec dist, State Anx, Dep \\
\hline Arver et al. ${ }^{42}$ & HBOC, HNPCC & Sweden & Base, $1 \mathrm{wk}, 2 \mathrm{mo}, 6 \mathrm{mo}, 12 \mathrm{mo}$ & Affective: Anx, Dep \\
\hline Botkin et al. ${ }^{16}$ & HBOC & US & Base, $1-2 \mathrm{wk}, 4-6 \mathrm{mo}, 12 \mathrm{mo}, 24 \mathrm{mo}$ & Behavior: Surv, Surg \\
\hline Claes et al. ${ }^{32,33}$ & HNPCC & Belgium & Base, 12 mo & $\begin{array}{l}\text { Perceived risk; Affective: Spec dist, State Anx; } \\
\text { Behavior: Surv }\end{array}$ \\
\hline Claes et al. ${ }^{17}$ & HBOC & Belgium & Base, $12 \mathrm{mo}$ & Perceived risk; Affective: Spec dist, State Anx \\
\hline Collins et al. ${ }^{34}$ & HNPCC & Australia & Base, $2 \mathrm{wk}, 4 \mathrm{mo}, 12 \mathrm{mo}$ & Behavior: Surv, Surg \\
\hline Gritz et al. ${ }^{35}$ & HNPCC & US & Base, $2 \mathrm{wk}, 6 \mathrm{mo}, 12 \mathrm{mo}$ & Perceived risk; Affective: State Anx, Dep, Worry \\
\hline Hadley et al. ${ }^{36}$ & HNPCC & US & Base, $6 \mathrm{mo}, 12 \mathrm{mo}$ & Behavior: Surv \\
\hline Halbert et al..$^{37}$ & HNPCC & US & Base, $1 \mathrm{mo}, 6 \mathrm{mo}, 12 \mathrm{mo}$ & Behavior: Surv \\
\hline Johnson et al. ${ }^{38}$ & HNPCC & US & Base, mean $12 \mathrm{mo}( \pm 3 \mathrm{mo})$ & Behavior: Surv \\
\hline Kinney et al. ${ }^{11,12}$ & HBOC & US & Base, 1 yr & Affective: Spec dist, Anx, Dep; Behavior: Surv and Surg \\
\hline Lerman et al. ${ }^{18}$ & HBOC & US & $1 \mathrm{mo}, 6 \mathrm{mo}, 12 \mathrm{mo}$ & Behavior: Surv and Surg \\
\hline Liede et al. ${ }^{14}$ & HBOC & Canada/US & Mean $2.2 \mathrm{yr}$ posttest & Behavior: Surv \\
\hline Lodder et al. ${ }^{19}$ & HBOC & Netherlands & Base, $1-3$ wk & Affective: Spec dist, Anx, Dep \\
\hline Lodder/van Oostrom et al. ${ }^{20-22}$ & НBOC & Netherlands & Base, $1-3 \mathrm{wk}, 6 \mathrm{mo}, 12 \mathrm{mo}, 5 \mathrm{yr}$ & $\begin{array}{l}\text { Affective: Spec dist, Anx, Dep, Worry; Behavior: Surv } \\
\text { and Surg }\end{array}$ \\
\hline Lynch et al. ${ }^{23}$ & HBOC & Canada/US & Base, mean $5.2 \mathrm{yr}$ posttest & $\begin{array}{l}\text { Affective: Gen dist, Worry, emotions, guilt; Behavior: } \\
\text { Surv and Surg }\end{array}$ \\
\hline Meijers-Heijboer et al. ${ }^{24}$ & HBOC & Netherlands & Median 26 mo posttest & Behavior: Surg \\
\hline Meiser et al. ${ }^{25}$ & HBOC & Australia & Base, 7-10 days, 4 mo, $12 \mathrm{mo}$ & Affective: Spec dist, State Anx, Dep \\
\hline Meiser et al. ${ }^{39}$ & HNPCC & Australia & Base, 7-10 days, 4 mo, 12 mo & Affective: Spec dist, State Anx, Dep \\
\hline Metcalfe et al. ${ }^{26}$ & HBOC & Canada/US & Mean 42.6 mo posttest & Behavior: Medication use, Surg \\
\hline Murakami et al. ${ }^{40}$ & HNPCC & Japan & Base, 1 mo & Affective: Presence/absence mental disorder \\
\hline Peshkin et al. ${ }^{27}$ & HBOC & US & Base, $1 \mathrm{mo}, 6 \mathrm{mo}, 12 \mathrm{mo}$ & Behavior: Surv \\
\hline Ponz de Leon et al. ${ }^{41}$ & HNPCC & Italy & $1-2 \mathrm{yr}$ & Behavior: Surv \\
\hline Reichelt et al. ${ }^{28}$ & HBOC & Norway & Base, 6 wk & Affective: Anx, Dep, Gen distr, Hopelessness \\
\hline Roberts et al. ${ }^{43}$ & $\mathrm{AD}$ & US & Base, $6 \mathrm{wk}, 6 \mathrm{mo}, 1 \mathrm{yr}$ & Affective: Anx; Behavior: General preventive behaviors \\
\hline Romero et al. ${ }^{44}$ & $\mathrm{AD}$ & US & Base, $1 \mathrm{mo}, 4 \mathrm{mo}, 10 \mathrm{mo}$ & Affective: Mood state, emotional reactions \\
\hline Schwartz et al. ${ }^{29}$ & HBOC & US & Base, 6 mo & Perceived risk; Affective: Spec dist, Gen distr \\
\hline van Roosmalen et a ${ }^{30}$ & HBOC & Netherlands & Base, $2 \mathrm{wk}$ & Affective: Spec dist, State Anx, Dep \\
\hline Watson et al. ${ }^{13}$ & HBOC & UK & Base, $1 \mathrm{mo}, 4 \mathrm{mo}, 12 \mathrm{mo}$ & $\begin{array}{l}\text { Perceived risk; Affective: Spec dist, Worry, Gen dist; } \\
\text { Behavior: Surv, Surg }\end{array}$ \\
\hline
\end{tabular}

HBOC, hereditary breast and ovarian cancer; HNPCC, hereditary nonpolyposis colorectal cancer; AD, Alzheimer disease; DS, disclosure session; Spec dist, disorder-specific distress; Anx, anxiety; Dep, depression; Gen dist, general distress; Worry, cancer worry; Surv, surveillance; Surg, prophylactic surgery.

of testing on anxiety levels. Of studies comparing anxiety levels in carriers and noncarriers, all reported no difference between groups.

For HNPCC, anxiety levels were generally increased in carriers in the short term (i.e., at disclosure of test results and 2 weeks' posttest), but had returned to baseline levels or lower by 12 months. Anxiety levels in noncarriers were decreased at disclosure of test results or 1-month posttest, but, as with carriers, had re- turned to baseline levels or lower by 12 months. Comparisons between carriers and noncarriers demonstrated that carriers generally had higher levels of anxiety than noncarriers at disclosure of test results, but at subsequent time points anxiety levels were similar between groups.

A single study examined the impacts of genetic testing for both HBOC and HNPCC on anxiety. ${ }^{42}$ Anxiety levels in both carriers and noncarriers decreased from pretest levels over the 
Heshka et al.

Table 3

General and specific outcomes used in the included studies

\begin{tabular}{ll}
\hline General outcome & \multicolumn{1}{c}{ Specific outcome } \\
\hline Affective & Perceived risk \\
& $\begin{array}{l}\text { Disorder-specific distress or worry } \\
\text { General or state anxiety } \\
\end{array}$ \\
& Depression \\
& General distress \\
& General health status \\
& Psychiatric diagnosis \\
& Surveillance behaviors \\
& Prophylactic surgery \\
& General preventive behaviors (i.e., diet, exercise, lifestyle)
\end{tabular}

course of 12 months and there were no differences between the two groups. Similarly, one study assessing anxiety after genetic testing for $\mathrm{AD}$ reported no differences between carriers and noncarriers at 6 weeks, 6 months, or 12 months.

\section{Depression}

Ten studies measured the impact of genetic testing for HBOC, HNPCC, and AD on depression using either the Center for Epidemiologic Studies Depression Scale or HADS. For all three diseases, the vast majority of studies reported no effect of genetic testing on depression scores in either carriers or noncarriers. Two studies, one on HBOC and the other on HNPCC, reported a brief increase in depression at 2 weeks posttest in carriers. ${ }^{30,35}$ Also, one study on HNPCC reported decreased depression scores at 1 month, ${ }^{44}$ whereas another found scores to be lower at 4 months. ${ }^{25}$ There were no differences in depression scores between groups for HBOC, HNPCC, or AD at any time point beyond 2 weeks.

\section{Worry}

Three studies, one each on HBOC, HNPCC, and AD, assessed the impact of genetic testing on worry. The results of these three studies were conflicting: one reported increased worry in carriers and decreased worry in noncarriers at 2 weeks, ${ }^{35}$ one found less worry in both carriers and noncarriers at 1 month, ${ }^{44}$ whereas the third reported increased worry in carriers compared with noncarriers throughout the 12-month follow-up period. ${ }^{13}$

\section{Behavioral outcomes}

The studies assessing behavioral outcome measures are summarized in Table 5. Self-reported screening practices and prophylactic surgery were the main outcome measures.

\section{Screening behavior}

For HBOC, behaviors assessed included mammography, breast self-examination (BSE), and clinical breast examination (CBE) for breast cancer screening, and transvaginal ultrasound and cancer antigen (Ca)-125 measurement for ovarian cancer screening. Additionally, one study examined the impact of genetic testing on the use of prostate-specific antigen and digital rectal examination for screening purposes in men.

Mammography screening rates for the 12 months after disclosure of genetic test results ranged from 59 to $92 \%$ in BRCA1/2 carriers and 30 to $53 \%$ in noncarriers. Most studies found that mammography rates increased in carriers postdisclosure in comparison with rates from the 12 months predisclosure. Although two studies reported increased 12-month rates in noncarriers as well, ${ }^{16}$ most studies found that mammography use was higher in carriers than in noncarriers. Similarly, while the use of BSE and CBE increased in both carriers and noncarriers after genetic testing, a greater proportion of carriers used these modalities than noncarriers. Combined use of BSE and CBE ranged from 90 to $95 \%$ in carriers and 77 to $89 \%$ in noncarriers.

Use of transvaginal ultrasound and Ca-125 for ovarian cancer screening after genetic testing was also increased to a greater extent in carriers than in noncarriers, with rates of these tests ranging from 15 to $59 \%$ and 21 to $32 \%$ in carriers, and 5 to $8 \%$ and 5 to $6 \%$ in noncarriers, respectively.

For HNPCC, the main behavioral outcome measure was having a colonoscopy. As with breast and ovarian cancer screening, colonoscopy increased within the 12 months after genetic testing in carriers in comparison with noncarriers. Rates of colonoscopy ranged from 58 to $100 \%$ in carriers and 0 to $40.5 \%$ in noncarriers. However, one study found decreased use of sigmoidoscopy or colonoscopy in carriers at 12 months compared with baseline or pretest levels. ${ }^{36}$

\section{Prophylactic surgery}

Eight studies reported rates of prophylactic surgery for HBOC in carriers in the 12 months after genetic testing. Rates varied from 0 to $51 \%$ for mastectomies and 13 to $65 \%$ for oophorectomies. One additional study on HNPCC found that 9.5\% of female carriers had had a hysterectomy in the 12 months postdisclosure. ${ }^{34}$

\section{Use of chemotherapeutics and other health-related behaviors}

Two studies found that $20-22.2 \%$ of female BRCA1/2 carriers were using or had used chemotherapeutics (i.e., tamoxifen, raloxifene) to prevent breast cancer. ${ }^{12,26}$ Also, two studies examined the impact of genetic testing on general health behaviors. ${ }^{13,43}$ Although $43-52 \%$ of subjects tested for HBOC reported having made lifestyle changes believed to promote health and/or reduce cancer risk (e.g., change diet, exercise, quit smoking) since being tested, both carriers and noncarriers, and males and females, made similar changes. Conversely, apolipoprotein $\mathrm{E} 4$ carriers were reported to be more likely than noncarriers to report engagement in activities believed to potentially lower their risk of $\mathrm{AD}$ after disclosure of genetic test results. 


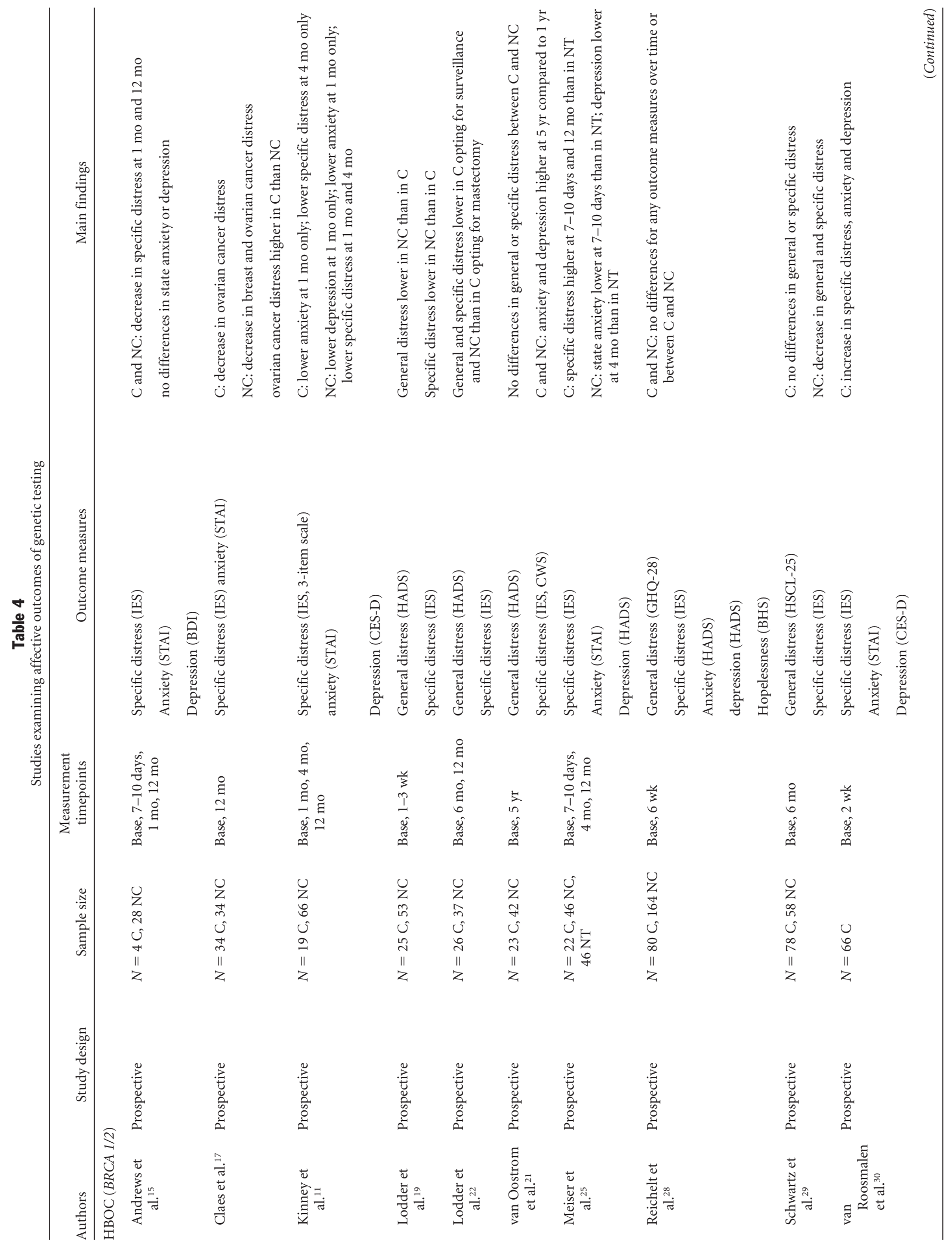




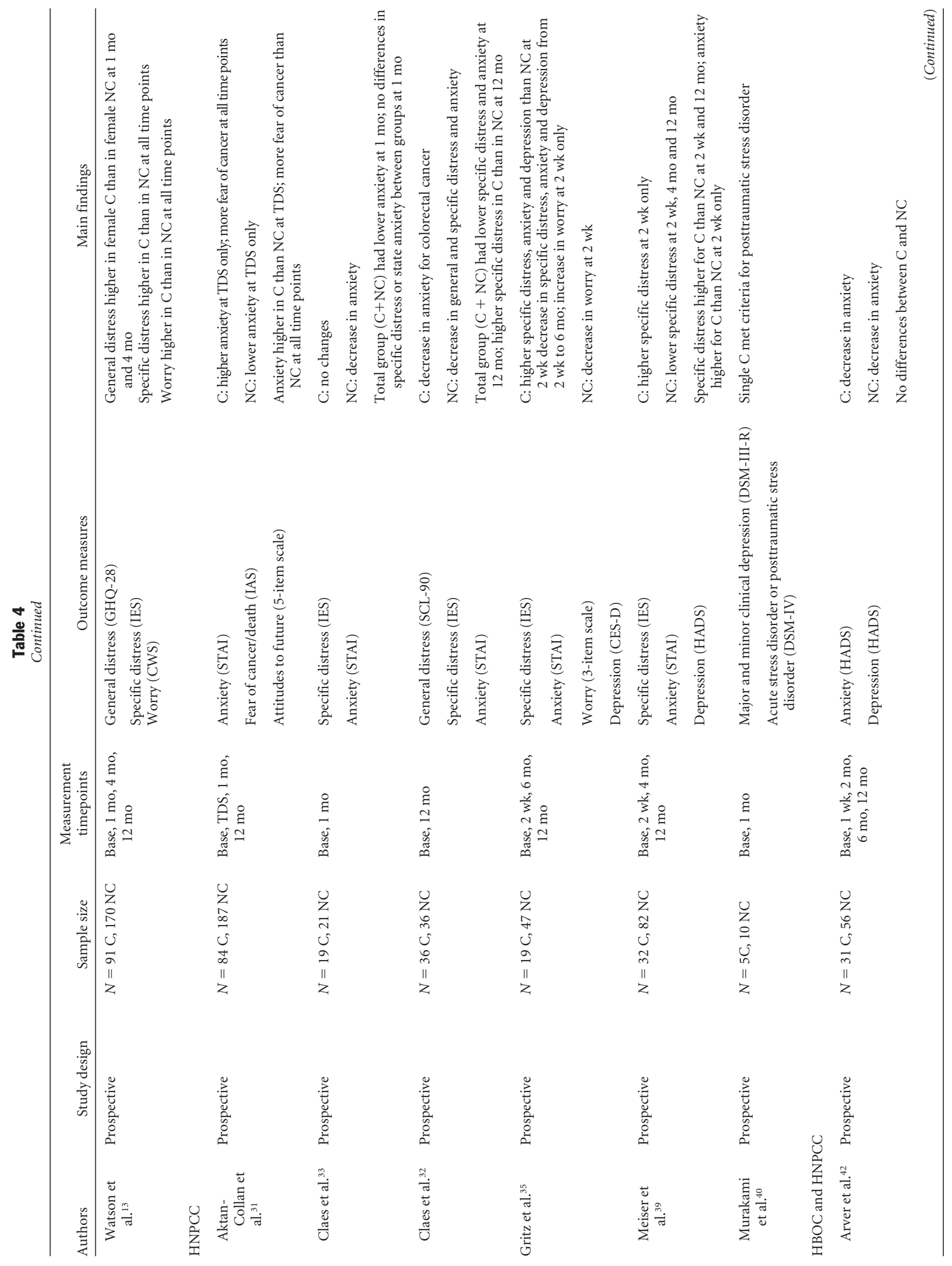




\section{Perceived risk}

The seven studies on HBOC and HNPCC that assessed risk perception after genetic testing are summarized in Table 6 . Although one study reported that noncarriers had lower perceived risk of $\mathrm{HBOC}$ than carriers at 6 months, ${ }^{29}$ there were generally no differences in risk perception of HBOC or HNPCC between carriers and noncarriers by 12 months after genetic testing. Two studies reported increased perceived risk in carriers in the short term (i.e., 1-month posttest), ${ }^{13,31}$ but overall risk perception in carriers was either the same or lower than pretest levels at 12 months. Nearly all studies found that perceived risk of HBOC and HNPCC in carriers was lower 12 months posttest compared with before undergoing genetic testing.

\section{DISCUSSION}

Genetic testing has the potential to reduce morbidity and mortality by enabling early identification of individuals at increased risk for various heritable conditions, thereby allowing targeted surveillance and management. Research has only recently begun to examine the effects of predictive and predispositional genetic testing on individuals and their families. Many reviews have focused patients after detection of a single mutation (e.g., $B R C A 1 / 2$ ), whereas others have focused only on psychological ${ }^{45-47}$ or behavioral outcomes. ${ }^{48}$ This review is the first, to our knowledge, to summarize the collective perceived risk, affective and behavioral impacts before and after predispositional genetic testing among unaffected individuals.

Reviews on the psychological impact of genetic testing have reported either no change in psychological outcomes among unaffected mutation carriers relative to baseline $e^{45,46}$ or decreased anxiety and worry after genetic testing. ${ }^{47}$ Meiser ${ }^{45}$ noted that some studies have consistently shown short-term increases in anxiety among unaffected carriers. Results regarding depression have been mixed. We found that overall genetic testing had no impact of psychological outcomes such as general and specific distress, anxiety, or depression in either carriers or noncarriers. These results held true regardless of the measurement tools used or whether results were reported separately (e.g., anxiety, depression) or combined (as for the results of general distress that may have also included anxiety and depression). We also noted the trend in some studies for there to be short-term (i.e., up to 4 months) increases in some of these measures among carriers, although this trend disappeared with time. The impact of genetic testing on worry was less clear and only a few studies in our review assessed this outcome measure.

Few reviews have evaluated the impact of genetic testing on screening practices and rates of prophylactic surgery. Behavioral outcome data were mainly limited to breast, ovarian, and colorectal cancer screening, and prophylactic surgery. Wainberg and Husted ${ }^{48}$ reported that rates of prophylactic mastectomy and oophorectomy among carriers varied between studies, but overall ranged from 0 to $54 \%$, and 13 to $53 \%$, 


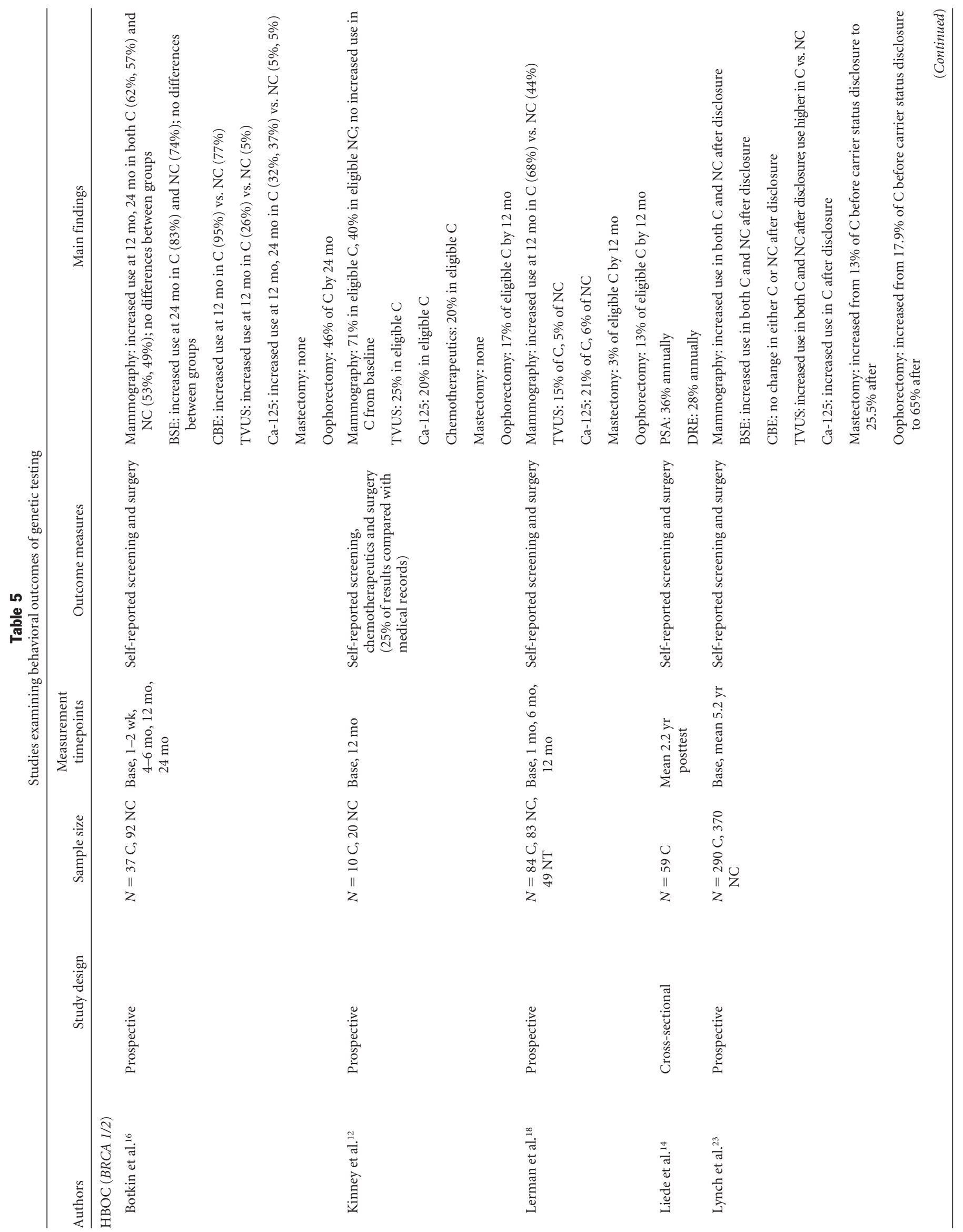




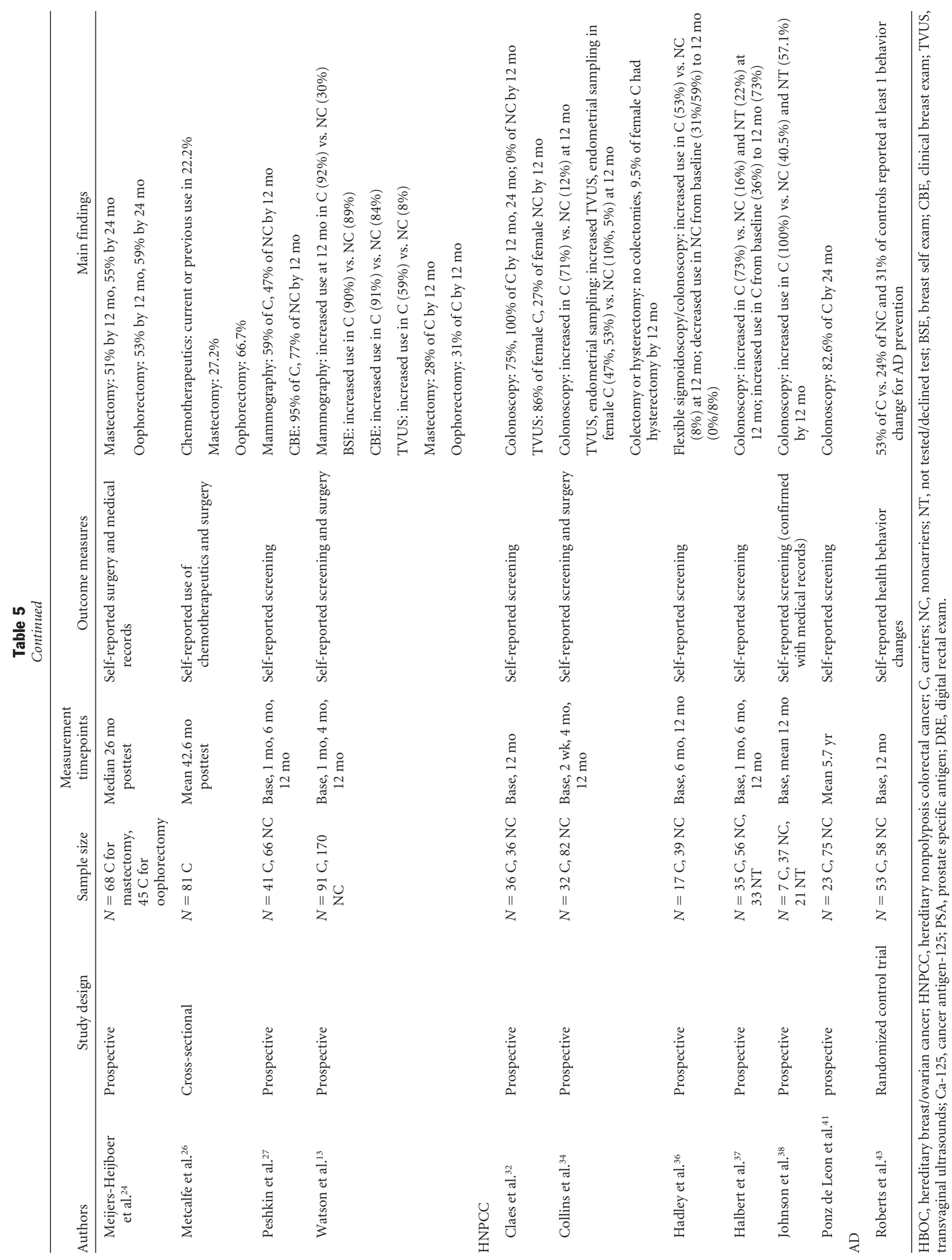


Table 6

Studies examining risk perception following genetic testing

\begin{tabular}{|c|c|c|c|c|c|}
\hline Authors & Study design & Sample size & $\begin{array}{l}\text { Measurement } \\
\text { timepoints }\end{array}$ & Instrument & Main findings \\
\hline \multicolumn{6}{|l|}{ HBOC (BRCA 1/2) } \\
\hline \multirow[t]{3}{*}{ Claes et al. ${ }^{17}$} & \multirow[t]{3}{*}{ Prospective } & \multirow[t]{3}{*}{$N=34 \mathrm{C}, 34 \mathrm{NC}$} & \multirow[t]{3}{*}{ Base, 12 mo } & \multirow[t]{3}{*}{$\begin{array}{l}\text { 2-item absolute assessment using } \\
\text { 5-point scale }\end{array}$} & $\begin{array}{l}\text { Decrease in breast and ovarian } \\
\text { cancer risk perception in NC }\end{array}$ \\
\hline & & & & & $\begin{array}{l}\text { Lower breast cancer risk } \\
\text { perception in NC vs. C }\end{array}$ \\
\hline & & & & & $\begin{array}{l}\text { No difference in ovarian risk } \\
\text { perception between } \mathrm{C} \text { and NC }\end{array}$ \\
\hline Schwartz et al. ${ }^{29}$ & Prospective & $N=35 \mathrm{C}, 58 \mathrm{NC}$ & Base, $1 \mathrm{mo}, 6 \mathrm{mo}$ & $\begin{array}{l}\text { 2-item absolute assessment using } \\
\text { 5-point scale }\end{array}$ & $\begin{array}{l}\text { Lower breast and ovarian cancer } \\
\text { risk perception in NC vs. C at } \\
6 \text { mo }\end{array}$ \\
\hline \multirow[t]{2}{*}{ Watson et al. ${ }^{13}$} & \multirow[t]{2}{*}{ Prospective } & \multirow[t]{2}{*}{$N=91 \mathrm{C}, 170 \mathrm{NC}$} & \multirow[t]{2}{*}{$\begin{array}{l}\text { Base, } 1 \mathrm{mo}, 4 \mathrm{mo} \text {, } \\
\quad 12 \mathrm{mo}\end{array}$} & \multirow{2}{*}{$\begin{array}{l}\text { 2-item absolute and comparative } \\
\text { assessments using 3-, 5-, and } \\
\text { 6-point scales }\end{array}$} & $\begin{array}{l}\text { Decrease in breast and ovarian } \\
\text { cancer risk perception in NC }\end{array}$ \\
\hline & & & & & $\begin{array}{l}\text { Increase in breast and ovarian } \\
\text { cancer risk perception in } \mathrm{C}<50 \\
\text { yr at } 1 \text { mo, but decrease to base } \\
\text { level by } 12 \text { mo }\end{array}$ \\
\hline \multicolumn{6}{|l|}{ HNPCC } \\
\hline $\begin{array}{l}\text { Aktan-Collan et } \\
\text { al. } .^{31}\end{array}$ & Prospective & $N=84 \mathrm{C}, 187 \mathrm{NC}$ & Base, $1 \mathrm{mo}, 12 \mathrm{mo}$ & $\begin{array}{l}\text { 1-item absolute assessment using } \\
\text { 3-point scale }\end{array}$ & $\begin{array}{l}\text { Decrease in colorectal cancer risk } \\
\text { perception from } 1 \text { mo to } 12 \mathrm{mo} \\
\text { in C }\end{array}$ \\
\hline \multirow[t]{2}{*}{ Claes et al. ${ }^{33}$} & \multirow[t]{2}{*}{ Prospective } & \multirow[t]{2}{*}{$N=19 \mathrm{C}, 21 \mathrm{NC}$} & \multirow[t]{2}{*}{ Base, 12 mo } & \multirow[t]{2}{*}{$\begin{array}{l}\text { 2-item absolute assessment using } \\
\text { 5-point scale }\end{array}$} & $\begin{array}{l}\text { Decrease in colorectal cancer risk } \\
\text { perception in NC }\end{array}$ \\
\hline & & & & & No change in risk perception in $\mathrm{C}$ \\
\hline Claes et al. ${ }^{32}$ & Prospective & $N=36 \mathrm{C}, 36 \mathrm{NC}$ & Base, 12 mo & $\begin{array}{l}\text { 2-item absolute assessment using } \\
5 \text {-point scale }\end{array}$ & $\begin{array}{l}\text { No difference in colorectal and } \\
\text { endometrial cancer risk } \\
\text { perception between C and NC }\end{array}$ \\
\hline Gritz et al. ${ }^{35}$ & Prospective & $N=19 \mathrm{C}, 47 \mathrm{NC}$ & $\begin{array}{l}\text { Base, } 2 \mathrm{wk}, 6 \mathrm{mo} \\
12 \mathrm{mo}\end{array}$ & $\begin{array}{l}\text { 1-item comparative assessment } \\
\text { using 5-point scale }\end{array}$ & $\begin{array}{l}\text { Decrease in colorectal cancer risk } \\
\text { perception in NC }\end{array}$ \\
\hline
\end{tabular}

respectively. Women tended to opt for oophorectomy slightly more often than mastectomy. This is consistent with our findings: rates of mastectomy and oophorectomy among our studies were 0 to $51 \%$, and 13 to $65 \%$, respectively. We also noted that women who opted for prophylactic surgery over surveillance tended to have surgery within the first year after genetic testing. Our review suggests that breast cancer screening rates are high and similar among carriers and noncarriers, whereas ovarian and colorectal cancer screening rates seem to be higher among carriers posttest compared with noncarriers. This may be attributable to the degree of invasiveness associated with screening procedures, but is also influenced by age of participants, as screening recommendations are different for older individuals than for younger. Studies on colonoscopy screening uptake among unaffected individuals suggest that most carriers underwent colonoscopy within 12 to 24 months after genetic testing.

In examining the impact of genetic testing on risk perception, we found that there were no differences between carriers and noncarriers by 12 months, and that risk perception was lower at that time point than at baseline in most studies. We would have expected perceived risk to be higher among carri- ers of genetic mutations than in noncarriers. Most studies included standard genetic counseling procedures that included information about the disease, its mode of inheritance, the gene defect, the benefits, risks and limitations of genetic testing, overview of screening recommendations, and treatment and preventive options. Only four studies did not mention or describe the counseling provided. ${ }^{13,21,35,40}$ It was not possible to determine whether there were differences in the quality or quantity of information provided. Furthermore, it is unclear how best to present information on genetic predisposition to patients and it would seem that this standard genetic counseling may not be effectively educating patients. Further research on the optimal methods for the provision of information is required. It is possible that the lack of major differences in psychological and behavioral outcomes is attributable to a lack of differences in risk perception between groups, because perceived risk is often a strong moderator of emotion and behavior.

Most of the studies included in this review acknowledged several limitations, at times limiting the precision of the results of these studies. Most study populations included small, selfselected samples that were not representative of all individuals 
eligible for testing. Claes et al. ${ }^{32}$ suggested that those individuals presenting for genetic testing may have a higher perceived ability to cope with their test result and that this may explain the relatively low distress levels found among study participants. Also, several studies that assessed the behavioral impacts of genetic testing noted that the study sample was highly motivated and already involved in pretest surveillance and/or likely to adhere to screening recommendations. Many studies reported homogenous samples that included predominantly white individuals with high levels of education. Some studies also had several participants from the same family, possibly producing family specific effects. As part of the research protocol, most studies included extensive pre- and posttest counseling and education, such that results may not be generalizable to a routine clinical setting. Genetic testing was usually offered free of charge, thus observed rates of testing may be higher than expected routinely. Finally, outcome measures for perceived risk were often not validated and those for behaviors were based on self-report, therefore have the potential for recall bias. Claes et al. ${ }^{33}$ suggested that distress measures used in the majority of these studies focus largely on detecting clinical disorder or psychopathology and may not be sensitive enough to capture the occurrence of negative emotional reactions in a "nonclinical" population.

A limitation of the present review is that a search of the gray literature, particularly conference abstracts, was not conducted, and so publication bias could not be completely eliminated. Also, the vast majority of studies included in our review examined the impacts of genetic testing for familial cancer, and with only two studies focused on AD. Studies that examined the impacts of testing for multifactorial disorders aside from cancer and $\mathrm{AD}$ (e.g., venous thrombosis and thrombophilia) were insufficiently rigorous to meet inclusion criteria. Because only two studies were in $\mathrm{AD}$ and genetic predispositional testing is not part of clinical care at this time, further review will be useful if testing becomes part of clinical practice.

Despite these limitations, our review provides valuable evidence regarding the perceived risk, affective, and behavioral impact of predisposition testing for various disorders. In general, the evidence suggests that genetic testing for these disorders does not seem to lead to adverse consequences for carriers or noncarriers. Further research is required to confirm the multiple impacts of genetic testing for multifactorial disorders, particularly in regards to risk perception, disorder-specific worry, and behavioral outcomes. Results of such research will be important in evaluating the wider impacts of genetic testing at both the level of the individual and the health care system.

\section{ACKNOWLEDGMENTS}

Dr. Wells is supported by a Canada Research Chair in Thromboembolic Disease from the Canada Research Chairs Program. A Heart \& Stroke Foundation of Ontario Program Grant PRG\#5513 helped fund this project.

\section{References}

1. Terdiman JP, Conrad PG, Sleisenger MH. Genetic testing in hereditary colorectal cancer: indications and procedures. Am J Gastroenterol 1999;94:2344-2356.

2. Peltomaki P, Aaltonen LA, Sistonen P, Pylkannen L, et al. Genetic mapping of a locus predisposing to human colorectal cancer. Science 1993;260:810-812.

3. Lindblom A, Tannergard P, Werelius B, Nordenskjold M. Genetic mapping of a second locus predisposing to hereditary non-polyposis colon cancer. Nat Genet 1993;5:279-282.

4. Nystrom-Lahti M, Parsons R, Sistonen P, Pylkkanen L, et al. Mismatch repair genes on chromosomes $2 \mathrm{p}$ and $3 \mathrm{p}$ account for a major share of hereditary nonpolyposis colorectal cancer families evaluable by linkage. Am J Hum Gen 1994; 55:659-665.

5. Nicolaides NC, Papadopoulos N, Liu B, Wei YF, et al. Mutations of two PMS homologues in hereditary non-polyposis colon cancer. Nature 1994;371:75-80.

6. Vasen HF, Wijnen JT, Menko FH, Kleibeuker JH, et al. Cancer risk in families with hereditary non-polyposis colorectal cancer diagnosed by mutation analysis. Gastroenterology 1996;110:1020-1027.

7. Aarnio M, Sankila R, Pukkala E, Salovaara R, et al. Cancer risk in mutation carriers of DNA mismatch repair genes. Int J Cancer 1999;81:214-218.

8. National Cancer Institute. Available at: http://www.cancer.gov/.

9. Cupples LA, Farrer LA, Sadovnik AD, Relkin N, et al. Estimating risk curves for first-degree relatives of patients with Alzheimer disease: the REVEAL study. Genet Med 2004;6:192-196.

10. Moher D, Cook DJ, Eastwood S, Olkin I, et al. Improving the quality of reports of meta-analysis of randomized controlled trials: the QUORUM statement. Lancet 1999;354:1896-1900.

11. Kinney AY, Bloor LE, Mandal D, Simonsen SE, et al. The impact of receiving genetic test results on general and cancer-specific psychologic distress among members of an African-American kindred with BRCAl mutation. Cancer 2005;104:2508-2516.

12. Kinney AY, Simonsen SE, Baty BJ, Mandal D, et al. Risk reduction behaviors and provider communication following genetic counseling and BRCA1 mutation testing in an African American kindred. J Genet Couns 2006;15:293-305.

13. Watson M, Foster C, Eeles R, Eccles D, et al. Psychosocial impact of breast/ovarian (BRCA1/2) cancer-predictive genetic testing in a UK multi-centre clinical cohort. Br J Cancer 2004;91:1787-1794.

14. Liede A, Metcalfe K, Hanna D, Hoodfar E, et al. Evaluation of the needs of male carriers of mutations in BRCA1 or BRCA2 who have undergone genetic counseling. Am J Hum Genet 2000;67:1494-1504.

15. Andrews L, Meiser B, Apicella C, Tucker K. Psychological impact of genetic testing for breast cancer susceptibility in women of Ashkenazi Jewish background: a prospective study. Genet Test 2004;8:240-247.

16. Botkin JR, Smith KR, Croyle RT, Baty BJ, et al. Genetic testing for a BRCAl mutation: prophylactic surgery and screening behavior in women 2 years post testing. Am J Med Genet 2003;118:201-209.

17. Claes E, Evers-Kiebooms G, Denayer L, Decruyenaere M, et al. Predictive genetic testing for hereditary breast and ovarian cancer: psychological distress and illness representations 1 year following disclosure. J Genet Couns 2005;14:349-363.

18. Lerman C, Hughes C, Croyle RT, Main D, et al. Prophylactic surgery decisions and surveillance practices one year following BRCA 1/2 testing. Prev Med 2000;31: 75-80.

19. Lodder L, Frets PG, Trijsburg RW, Tibben A, et al. Men at risk of being a mutation carrier for hereditary breast/ovarian cancer: an exploration of attitudes and psychological functioning during genetic testing. Eur J Hum Genet 2001;9:492-500.

20. Lodder L, Frets PG, Trijsburg RW, Meijers-Heijboer, et al. Psychological impact of receiving a BRCA1/BRCA2 test result. Am J Med Genet 2001;98:15-24.

21. van Oostrom I, Meijers-Heijboer H, Lodder LN, Duivenvoorden HJ, et al. Longterm psychological impact of carrying a BRCA1/2 mutation and prophylactic surgery: a 5-year follow-up study. J Clin Oncol 2003;21:3867-3874.

22. Lodder LN, Frets PG, Trijsburg RW, Meijers-Heijboer EJ, et al. One year follow-up of women opting for presymptomatic testing for BRCA1 and BRCA2: emotional impact of the test outcome and decisions on risk management (surveillance or prophylactic surgery). Breast Cancer Res Treat 2002;73:97-112.

23. Lynch HT, Snyder C, Lynch JF, Karatoprakli P, et al. Patient responses to the disclosure of BRCA mutation tests in hereditary breast-ovarian cancer families. Cancer Genet Cytogenet 2006;165:91-97.

24. Meijers-Heijboer E, Verhoog L, Brekelmans C, Seynaeve C, et al. Presymptomatic DNA testing and prophylactic surgery in families with a BRCA1 or BRCA2 mutation. Lancet 2000;355:2015-2020.

25. Meiser B, Butow P, Friedlander M, Barratt A, et al. Psychological impact of genetic testing in women from high-risk breast cancer families. Eur J Cancer 2002;38:20252031.

26. Metcalfe KA, Snyder C, Seidel J, Hanna D, et al. The use of preventive measures among healthy women who carry a BRCA1 or BRCA2 mutation. Fam Cancer 2005; 4:97-103. 
27. Peshkin BN, Schwartz MD, Isaacs C, Hughes C, et al. Utilization of breast cancer screening in a clinically based sample of women after BRCA1/2 testing. Cancer Epidemiol Biomarkers Prev 2002;11:1115-1118.

28. Reichelt JG, Heimdal K, Moller P, Dahl AA. BRCA1 testing with definitive results: a prospective study of psychological distress in a large clinic-based sample. Fam Cancer 2004;3:21-28.

29. Schwartz MD, Peshkin BN, Hughes C, Main D, et al. Impact of BRCA1/BRCA2 mutation testing on psychologic distress in a clinic-based sample. J Clin Oncol 2002; 20:514-520.

30. van Roosmalen MS, Stalmeier PF, Verhoef LC, Hoekstra-Weebers JE, et al. Impact of BRCA1/2 testing and disclosure of a positive test result on women affected and unaffected with breast or ovarian cancer. Am J Med Genet 2004;124:346-355.

31. Aktan-Collan K, Haukkala A, Mecklin JP, Uutela A, et al. Comprehension of cancer risk one and 12 months after predictive genetic testing for hereditary non-polyposis colorectal cancer. J Med Genet 2001;38:787-792.

32. Claes E, Denayer L, Evers-Kiebooms G, Boogaerts A, et al. Predictive testing for hereditary nonpolyposis colorectal cancer: subjective perception regarding colorectal and endometrial cancer, distress, and health-related behavior at one year posttest. Genet Test 2005;9:54-65.

33. Claes E, Denayer L, Evers-Kiebooms G, Boogaerts A, et al. Predictive testing for hereditary non-polyposis colorectal cancer: motivation, illness representations and short-term psychological impact. Patient Educ Couns 2004;55:265-274.

34. Collins V, Meiser B, Gaff C, St John DJ, et al. Screening and preventive behaviors one year after predictive genetic testing for hereditary nonpolyposis colorectal carcinoma. Cancer 2005; 104:273-281.

35. Gritz ER, Peterson SK, Vernon SW, Marani SK, et al. Psychological impact of genetic testing for hereditary nonpolyposis colorectal cancer. J Clin Oncol 2005;23:19021910.

36. Hadley DW, Jenkins JF, Dimond E, de Carvalho M, et al. Colon cancer screening practices after genetic counseling and testing for hereditary nonpolyposis colorectal cancer. J Clin Oncol 2004;22:39-44.
37. Halbert $\mathrm{CH}$, Lynch $\mathrm{H}$, Lynch J, Main D, et al. Colon cancer screening practices following genetic testing for hereditary nonpolyposis colon cancer (HNPCC) mutations. Arch Intern Med 2004;164:1881-1887.

38. Johnson KA, Trimbath JD, Petersen GM, Griffin CA, et al. Impact of genetic counseling and testing on colorectal cancer screening behaviour. Genet Test 2002;6:303-306.

39. Meiser B, Collins V, Warren R, Gaff C, et al. Psychological impact of genetic testing for hereditary non-polyposis colorectal cancer. Clin Genet 2004;66:502-511.

40. Murakami Y, Okamura H, Sugano K, Yoshida T, et al. Psychologic distress after disclosure of genetic test results regarding hereditary nonpolyposis colorectal carcinoma. Cancer 2004;101:395-403.

41. Ponz de Leon M, Benatti P, Di Gregorio C, Pedroni M, et al. Genetic testing among high-risk individuals in families with hereditary nonpolyposis colorectal cancer. $\mathrm{Br} \mathrm{J}$ Cancer 2004;90:882-887.

42. Arver B, Haegermark A, Platten U, Lindblom A, et al. Evaluation of psychosocial effects of pre-symptomatic testing for breast/ovarian and colon cancer pre-disposing genes: a 12-month follow-up. Fam Cancer 2004;3:109-116.

43. Roberts JS, Cupples LA, Relkin NR, Whitehouse PJ, et al. Genetic risk assessment for adult children of people with Alzeimer's Disease: the risk evaluation and education for Alzeimer's Disease (REVEAL) Study. J Geriatr Psychiatry Neurol 2005;18:250-255.

44. Romero LJ, Garry PJ, Schuyler M, Bennahum DA, et al. Emotional responses to APO E genotype disclosure for Alzheimer disease. J Genet Couns 2005;14:141-150.

45. Meiser B. Psychological impact of genetic testing for cancer susceptibility: an update of the literature. Psychooncology 2005;14:1060-1074.

46. Schlich-Bakker KJ, ten Kroode HFJ, Ausems MG. A literature review of the psychological impact of genetic testing on breast cancer patients. Patient Educ Couns 2006; 62:13-20.

47. Nelson HD, Huffman LH, Fu R, Harris EL. Genetic risk assessment and BRCA mutation testing for breast and ovarian cancer susceptibility: systematic evidence review for the U.S. preventive services task force. Ann Intern Med 2005;143:362-379.

48. Wainberg S, Husted J. Utilization of screening and preventive surgery among unaffected carriers of BRCA1 or BRCA2 gene mutation. Cancer Epidemiol Biomarkers Prev 2004;13:1989-1995. 